\title{
Coding Forum: A Timely Scenario (Spring 1986)
}

Gilbert Martin, MD

\section{Funding for Neonatology}

The following scenario was written in 1986. Although tonguein-cheek, and imaginative some of the principles regarding the need for Federal and State Funding to support perinatal research, remuneration for hospitals and personnel remain cogent today. The bottom line is always "money." In today's world (2021), healthcare workers, administrators, and legislators understand the challenge and principles of funding for perinatal and neonatal issues. The song at the end of this scenario has been recorded on a CD. If you would like a copy, email me at gimartinmd@ yahoo.com, and I will send you one.

"Although farming, education, and social security programs were axed initially, the health care industry was now feeling the crunch. For the first time in the decade, the fetal and neonatal mortality figures were rising, for there was not enough money to pay for either personnel or needed equipment. Research was not funded, scientists were leaving the medical profession in droves, and the gloom and doom attitude was now a reality."

The news was not good. The government, facing an even larger deficit in 1994 than expected, was recommending another "austerity program." The expansion of the "Star Wars" defense system and the continual threat from orbiting "Galactic Foreign Plopods" allowed the administration to triple the defense budget at the expense of other programs. Although farming, education, and social security programs were axed initially, the health care industry was now feeling the crunch. For the first time in the decade, the fetal and neonatal mortality figures were rising, for there was not enough money to pay for either personnel or needed equipment. Research was not funded, scientists were leaving the

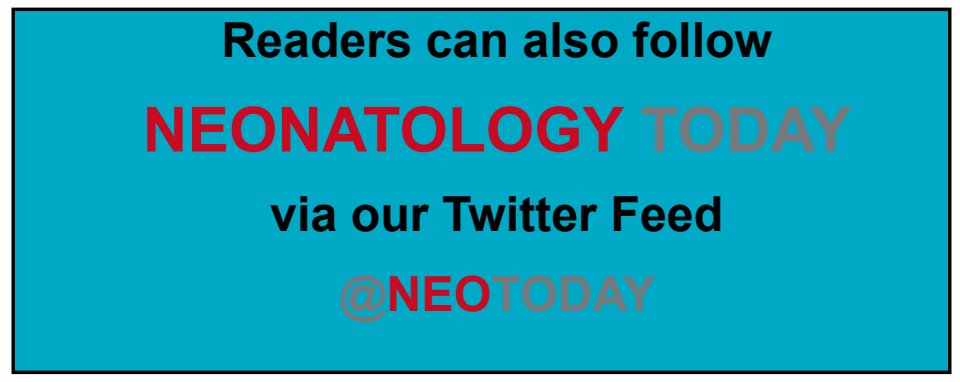

medical profession in droves, and the gloom and doom attitude was now a reality.

In August, I was asked to join a select panel of Neonatologists from the Perinatal Section of the American Academy of Pediatrics. A meeting was held in Washington, D.C., and I noted that the American College of Obstetrics and Gynecology hand sent delegates as well. After initial informal introductions and renewed hellos, we were asked to sit around an oblong table in a stately room near the Capital. The twelve of us were an interesting bunch, I mused. Three pediatricians, three neonatologists, three obstetricians, and three perinatologists. I noted, too, that not only were the seating arrangements such that the specialties were kept together but within each group of three, there were well-defined age categories. It seemed that there was one physician in the 30-40 age category, one 41-50, and one other in the 51-60 range. Probably a coincidence, I thought...but...I wonder.....

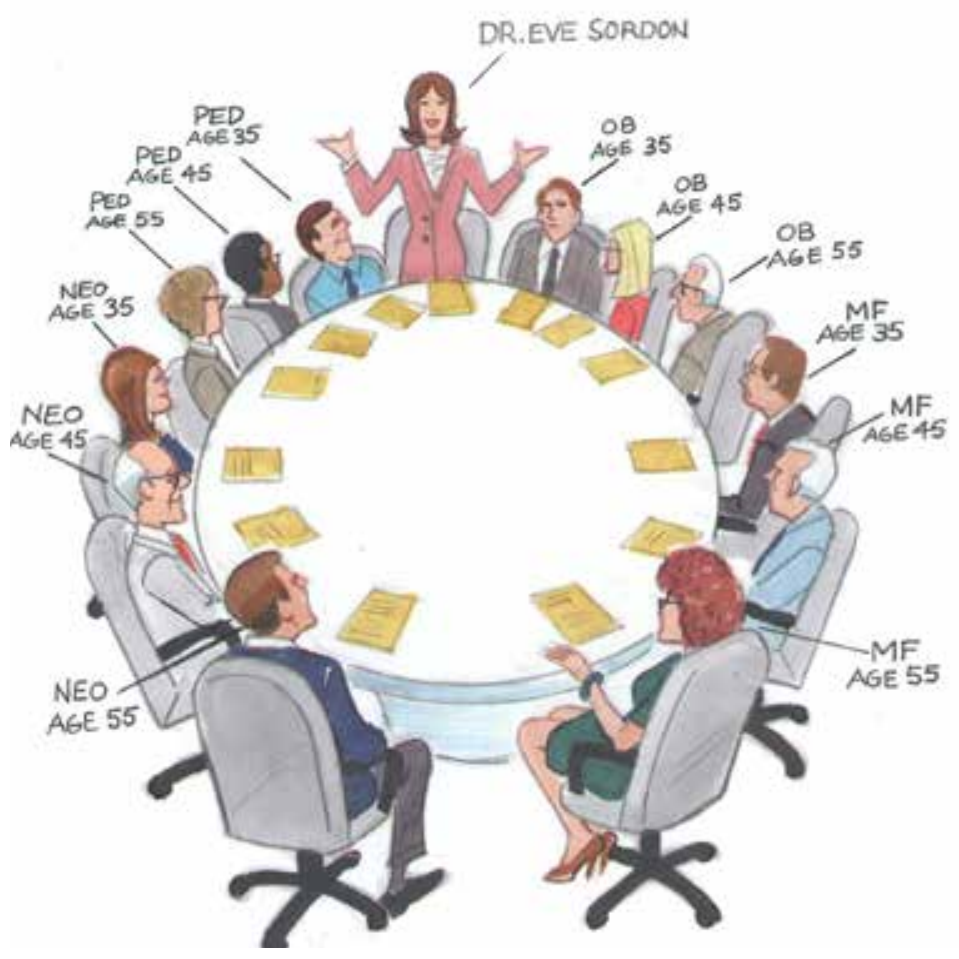

"Ladies and Gentlemen, I wonder if we might get down to business," began Dr. Eve Sordon, the President of the National Perinatal Coalition. "As you well know, Congress is about to pass the Kennedy-Glenn Bill, which will literally cut off federal funds for perinatal research, tighten the DRGs for perinatal medicine, and only allow tertiary or quaternary centers to operate. Since so many of the old primary hospital centers closed in 1991 and 1992, much of the rural American population has been left without hospitals to care for both mother and infant, and inappropriate and unexpected home deliveries have increased. The rest you know about. First, fetal and neonatal mortality increased. In the last six 
months, both maternal morbidity and mortality have also risen. The bottom line is money. We need to raise 100 million dollars quickly to infuse into the system."

An immediate low-pitched buzzing was heard as the physicians reacted to Dr. Sordon's statement.

"Eve," began Phil Gurman, one of the neonatologists. "Isn't this a bit out of our league?" We are physicians, not fundraisers or legislators. I am sure that Polly and Saul would also agree."

"Hold on a minute, Phil. Look around the room at the other people that are on this committee. All of you have something in common. You were not only chosen because of your expertise in your particular field, but every person in this room has a secondary interest which can be used to help raise the money."

I looked around again. No oil money here, I thought. I don't see any fancy jewelry, and I can't remember limousines downstairs. Ordinary dress with gray slacks and blue blazers...no Bijan silk suits here. Now in.....

Eve motioned for quiet again.

"It's time to explain. Each of you has been either professional athletes, musicians, actors, or actresses before becoming physicians. Since all the "big money" today resides in these three fields, we felt that we would like to set up a big athletic event, like a super-super bowl. At half-time, a large number of famous people would come on to the field, join hands, and sing a song, which then would be flashed on the screen and sung by everybody. The song would be so full of nationalism and feeling that it would then be recorded, sold in the stores, and the profits from the game and the records would make up the deficit."

Everyone thought of the same thing. In 1984, "We are the Children" made millions for the people in Africa. In 1986, "Hands Across American" sold 18 million records and was worth 80 million dollars.

The buzz returned.

There was great excitement in the room. Dates, times, places, and ideas were all thrown out for discussion and either discarded or agreed upon. The final questions dealt with who should write and record the song. The older group wanted Sinatra or Streisand. The middle group opted for Manilow or Diamond. The younger group only wanted Springsteen, The Boss.

Finally, Eve called for attention.

"Please, please," she began. "All this arguing over who and how will do us no good. We have among us someone who has experience in the recording business and who would be perfect."

Her gaze turned to me, and all eyes followed.

"Perry, you write and record the song."

On October 15, 1994, the event was held in the new 180,000seat American Stadium. The song, Let Our Babies Grow" brought tears to the eyes of all people everywhere. During the first 12 weeks of production, the song written and performed by Perry Nate was at the top of all Billboard charts.
The rest.....is history.

"Let Our Babies Grow"

Words and music by Perry Nate

Verse

Verse

In this day and age

Knowledge, care, and money

We often wonder why.

Will help our babies 'cause

Seems there is no greater sound,

Stand up tall-ask for all,

A newborn baby's cry.

Break down these closed doors.

It means an early start,

Don't allow a very few

Which hopefully will last.

To spoil it for the rest

The cry looks to be the future

America must take the step,

And wipes away the past

Its kids deserve the best.

\section{Chorus}

Chorus

Give us the heart and hope

Give us the heart and hope

To let our babies grow.

To let our babies grow.

Make sure the care is such, Make sure the care is such,

So we are in the know.

So we are in the know.

Let our babies grow with love,

Let our babies grow with love,

Allow them all this chance, Allow them all this chance,

Watch them coo, and talk, and walk, Watch them coo, and talk, and walk,

Watch them run and dance.

Watch them run and dance. 
The author has no conflicts of interests to disclose.

NT

Corresponding Author

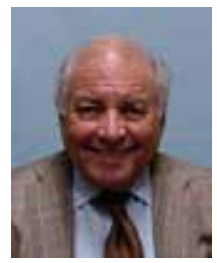

Gilbert I Martin, MD, FAAP

Division of Neonatal Medicine

Department of Pediatrics

Professor of Pediatrics

Loma Linda University School of Medicine

Email:gimartin@llu.edu

Office Phone: 909-558-7448
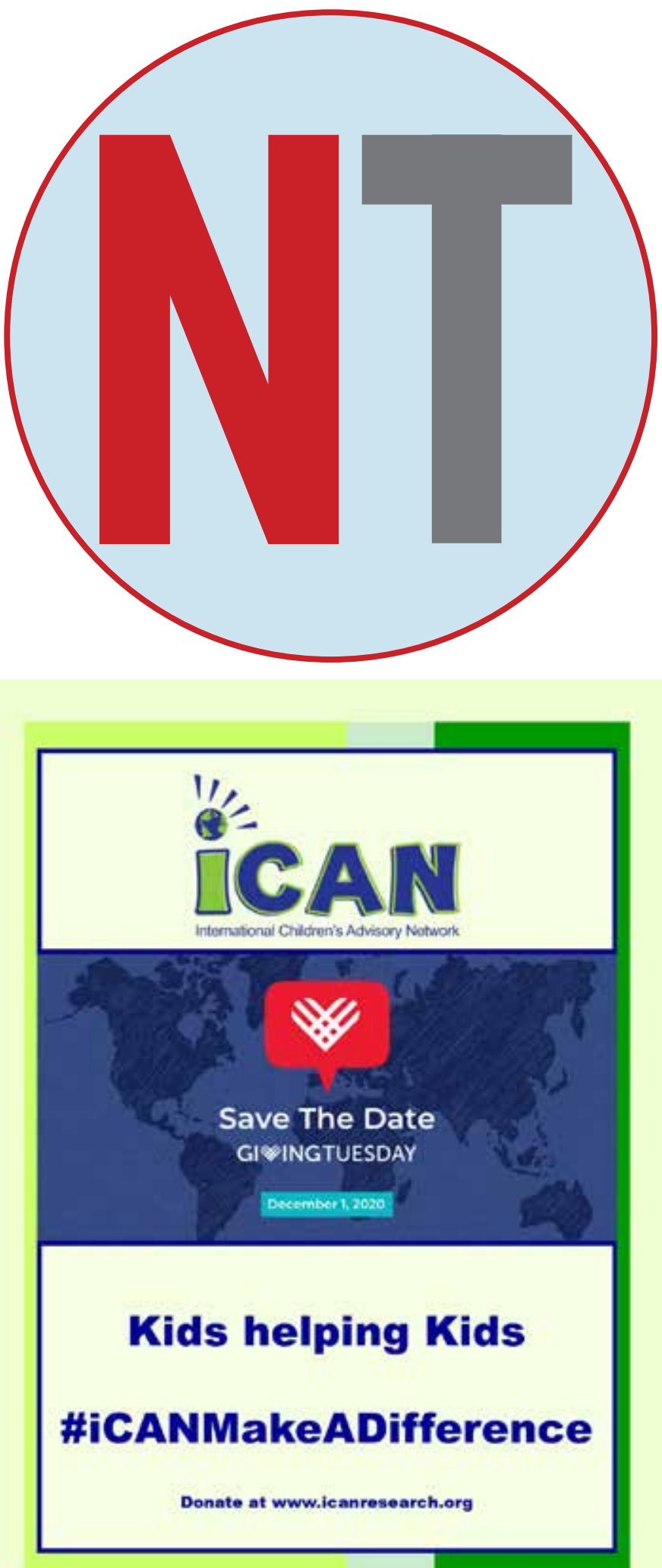

Oo National Perinatal Association PERINATAL SUBSTANCE USE

nationalperinatal.org/position

www.nationalperinatal.org/Substance_Use

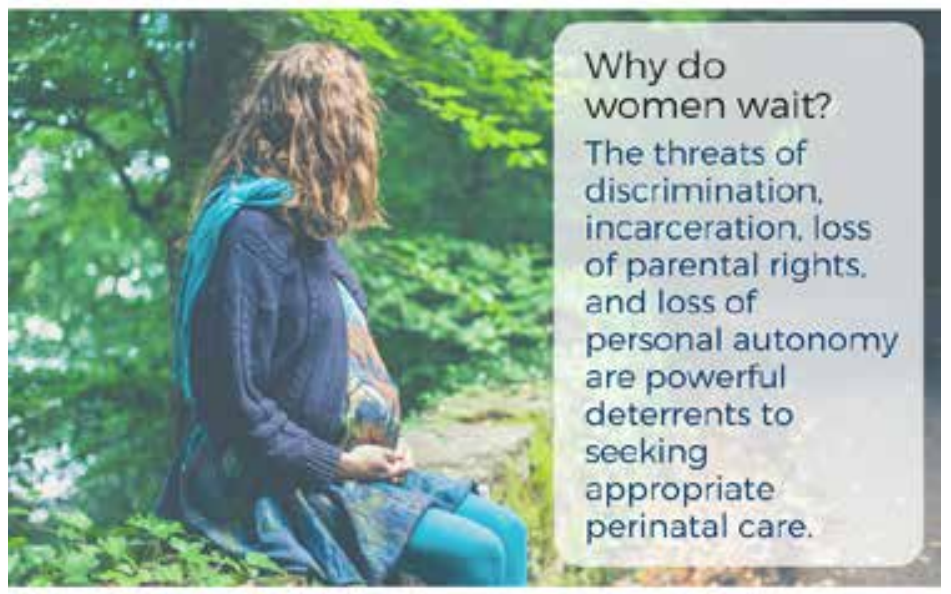

Educate. Advocate. Integrate.
Why do women wait? The threats of discrimination. carceration loss personal autonomy are powerful deterrents to seeking appropriate atal care. 